\title{
The EC and real estate rents in Brussels*
}

\author{
by \\ Victor Ginsburgh \\ Université Libre de Bruxelles and CORE \\ and \\ Patrick Waelbroeck \\ Université Libre de Bruxelles
}

August 1995

Abstract.

Real estate prices in Brussels started to increase at a very rapid rate in 1987-1988. This happened a few years before the European Community had to decide whether the Commission would remain in Brussels, and whether the European Parliament would be moved to Brussels; this was compounded by the fact that prices were (and still are) much lower than in most other European cities. The main purpose of the paper is to analyze how the European Community influenced real estate rents in Brussels during the period 19801992, and to isolate the EC effects from other effects. The rents due to the EC appear to be quite high at a close neighbourhood of the EC main offices (the increase is some $90 \%$ above the "normal" price at a distance of $500 \mathrm{~m}$ ), but even further away, prices have been influenced $(+25 \%$ at $3,000 \mathrm{~m})$.

Puiblished Regional Science and Urban Economics 28 (1998), 497-511.

\footnotetext{
* We are grateful to Claude Denis for having allowed us to use her database on house transactions in Brussels. Mr Keller from the EC as well as the Service de Documentation du Soir were kind enough to provide several pieces of factual information. Financial support from the Belgian Government under Contract PAI n ${ }^{\circ} 26$ is gratefully acknowledged. This work was triggered by a conference Jacques Drèze gave a few years ago at the Société Royale d'Economie Politique de Belgique. See Drèze (1992).
} 


\section{Introduction}

After a long period of depression, real estate prices started to increase at a more rapid rate in Brussels than in other Belgian larger cities as of 1987-1988. This led some economists, including Drèze (1995), to argue that these "land rent appreciations" were mainly due to the presence of the European Community in Brussels and that they should be used to achieve a more efficient urban organization.

This rapid price increase took place a few years before the European Community had to decide whether the Commission would remain in Brussels, and whether the European Parliament would be moved to Brussels. Though in 1988, nobody could anticipate with certainty what would happen with the Parliament, it was quite unlikely that the Commission's administrative headquarters would be moved from Brussels to some other place. ${ }^{1}$ It is also worth emphasizing that "1992" and the Single European Market was getting closer and, at that time at least, expectations were "great."

There are thus reasons to think that the decisions that were to come, could greatly influence real estate prices in Brussels; this was compounded by the fact that prices were (and still are) much lower than in most other European cities. ${ }^{2}$

It however so happened that prices in other European cities, like Paris and London, soared at about the same time, and this makes it more difficult to disentangle the BrusselsEC effect from the general price increase which would have taken place in the absence of the European bureaucracy.

The main purpose of the paper is to isolate the EC effects from other effects; we therefore have to "clean" as much as possible real estate prices from all non-EC effects, and isolate the latter. The paper is organized as follows. The methodology is presented in Section 2. Empirical results, based on two different approaches, are discussed in Section 3, while Section 4 draws some conclusions.

\footnotetext{
1 The decision to maintain the location of the EC headquarters in Brussels was eventually made in December 1992 at a European Meeting in Edinburgh.

2 In 1992, a four bedroom house in a good area in Brussels was three times cheaper than in Frankfurt or New York ((\$280,000), \$765,000 and \$800,000 respectively). See The Economist, December 26, 1992. Office rents were a bit higher than in Amsterdam, but worth one third or one fourth of what they were in Paris' Golden Triangle or in London's West End respectively. See Jones Lang Wooton, City Report Brussels, 1992.
} 


\section{Methodology}

The main purpose of this article is to determine whether the EC has generated real estate rents, and if these rents have increased through time or, in other words, whether land rent appreciation has taken place.

In a specific urban area, the amount of land available can be assumed fixed. Hence, the competitive rent for land is mainly determined by demand. Land rent $^{3}$ is defined as the difference between the competitive rent and the agricultural rent, that is the rent that prevails at the border of the city in the standard monocentric city model. Demand, however, changes as the willingness to pay for land increases (for instance, because of changes in expected land value improvements) or as the number of demanders increases. In this case, land rent appreciation in a specific urban area is defined as the difference between the land rent before and after the change of the demand for land. In this article, we use the monocentric city model as the underlying framework. This is not too restrictive since Brussels is known as being monocentric: the central business district roughly coincides with the EC centre.

We shall use a hedonic approach to homogenize houses in order to compute land rents. Bailey, Muth and Nourse (1963) were the first to use hedonic regressions to evaluate real estate price indices. Rosen (1974) and, later on, Brown and Rosen (1982), Bartik (1987), Epple (1987) and others have stressed that the coefficients estimated in these regressions should be interpreted with care, since the hedonic equation merely represents the locus of equilibrium prices for characteristics and gives no information on the parameters of demands and supplies for such characteristics. The technique has nevertheless been continuously used to construct price indices. ${ }^{4}$

For that purpose, hedonic regression is an alternative to repeat sales regression techniques which use resales only to compute price indices. ${ }^{5}$ In repeat sales techniques, one can compute the price increase of each item sold and there is, in principle, no need to take into account heterogeneity of the items (abstracting from the fact that quality may have changed between sales).

\footnotetext{
3 Some authors call it the differential land rent.

4 See among others Case and Quigley (1991), Grether and Mieszkowski (1974), Halvorsen and Pollakowski (1981), Li and Brown (1980), Linneman (1980) and Palmquist (1980, 1982). Witte, Sumka and Erekson (1979), Nelson (1978) and Palmquist (1984) have followed Rosen's (1974) suggestion to estimate the structural form of supply and demand functions for housing characteristics, and not only the hedonic price equation.

5 See Palmquist (1980) for a comparison of price indices obtained from repeat sales and hedonic estimation and Shiller (1991) for a comprehensive overview of repeat sales regression, and for the differences between arithmetic and geometric estimators.
} 
Hedonic regression, on the other hand, can be interpreted as a two step procedure. In the first step, one estimates the implicit price $\beta_{\mathrm{k}}$ for characteristic $\mathrm{x}_{\mathrm{k}}(\mathrm{k}=1,2, \ldots, \mathrm{K})$ and "corrects" the observed (log of the) price $p_{i t}$ of item i sold in year $t$, by subtracting from $\ln p_{i t}$ the value of the characteristics which it embodies. This leads to a characteristic free price $\pi_{\mathrm{it}}$ :

$$
\pi_{\mathrm{it}}=\ln \mathrm{p}_{\mathrm{it}}-\Sigma_{\mathrm{k}} \beta_{\mathrm{k}} \mathrm{x}_{\mathrm{k}, \mathrm{it}},
$$

for commodities that can now be considered as homogeneous. The second step of the procedure simply consists in computing the mean $\alpha_{t}=\Sigma_{i} \pi_{i t} / n_{t}$ which represents, the (geometric) average price of the $n_{t}$ "identical" (up to an error $\varepsilon_{i t}$ ) items sold during year $t$.

Obviously, $\alpha_{t}$ is no more than the intercept of the regression of $\ln p_{i t}$ on the characteristics $\mathrm{x}_{\mathrm{it}}$ in year $\mathrm{t}$. If one assumes that the prices of characteristics do not change over time, ${ }^{6}$ one can, within a unique regression, treat observations belonging to several years $\tau=1,2, \ldots, \mathrm{T}$ and estimate the coefficients of the following model:

$$
\ln p_{i t}=\Sigma_{k} \beta_{k} x_{k, i t}+\Sigma_{\tau} \alpha_{\tau} y_{\tau, \text { it }}+\varepsilon_{i t}
$$

where $y_{\tau}$,it is a dummy variable which takes the value one if $\tau=t$ for item $i$, and zero otherwise. The sequence of $\alpha_{\tau}$ 's $(\tau=1,2, \ldots, \mathrm{T})$ can now be used to construct a price index.

The model can obviously take account of characteristics which change over time. If we denote by $\mathrm{K}_{1} \in \mathrm{K}$, the subset of such characteristics, (2.2) can be written:

$$
\ln \mathrm{p}_{\mathrm{it}}=\Sigma_{\mathrm{k} \in \mathrm{K}_{1}} \beta_{\mathrm{kt}} \mathrm{x}_{\mathrm{k}, \mathrm{it}}+\Sigma_{\mathrm{k} \notin \mathrm{K}_{1}} \beta_{\mathrm{k}} \mathrm{x}_{\mathrm{k}, \mathrm{it}}+\Sigma_{\tau} \alpha_{\tau} \mathrm{y}_{\tau, \mathrm{it}}+\varepsilon_{\mathrm{it}}
$$

Hedonic regression has some advantage over repeat sales estimators. Indeed, collecting data on sales is obviously much easier than pairing resales data. Moreover, the number of sales is much larger than the number of resales, and using sales within a hedonic regression framework may be thought to lead to more precise estimates than those obtained by repeat sales estimators. ${ }^{7}$

\footnotetext{
6 This can of course be tested.

7 See Chanel et al. (1992). This is the case even when the number of observations used in both methods is the same.
} 
Within this framework, we are now ready to see how the EC presence influenced real estate prices in Brussels. We ascribe rents resulting from the installation of the EC in Brussels to two reasons mainly: (1) the demand for offices by the European bureaucracy itself as well as by the lobbyists who follow may end up raising the prices of closeby located housing opportunities; the effect will be compounded by the development of hotels, restaurants and the general improvement of infrastructure; (2) the rumors since 1987 that the Commission would keep its headquarters in Brussels and could hold there some of the sessions of the European Parliament, together with the expectations generated by "1992," may clearly also have contributed to increase residential property values. Though the final decision to keep the headquarters of the EC administration in Brussels and to hold additional sessions of the European Parliament in Brussels was taken in Edinburgh in December 1992, rumors had started to spread much earlier; moreover, the building supposed to locate the Parliament was started in January 1989, long before the Edinburgh final decision. ${ }^{8}$

\section{Proximity to EC headquarters}

It is easy to test whether the EC headquarters have an influence on property values, by introducing into (2.2) variables which measure the distance of a property to the headquarters: proximity will in principle increase prices, but this effect should decrease with distance. To examine the hypothesis, we have constructed different classes of houses, according to their distance to the EC center (see Appendix 1 for details) and a coefficient will be estimated for each class. The proximity effect on property $i$ is thus represented by:

$$
\operatorname{prox}_{\mathrm{i}}=\Sigma_{\mathrm{q}} \xi_{\mathrm{q}} \mathrm{h}_{\mathrm{q}, \mathrm{i}}
$$

where $h_{\mathrm{q}, \mathrm{i}}$ is a dummy variable which takes the value one if a property belongs to proximity class $\mathrm{q}$, and zero otherwise and the $\xi_{\mathrm{q}}$ are parameters to be estimated. Note that instead of using classes, we could have simply estimated a convex function $\operatorname{prox}\left(\mathrm{D}_{\mathrm{i}}\right)$; this would have forced a regular functional form on the data and we thought that more flexibility would be better. Formulation (2.4) is used in the equation estimated by ordinary least squares.

Proximity however can also have negative effects: high-rise office buildings may destroy the view and other aesthetic qualities of a surrounding; a high density of offices

\footnotetext{
${ }^{8}$ Newspapers in Brussels report on this and clearly state that the building will locate sessions as well as the administrative services of the European Parliament. See e.g. Le Soir, January 12, 1989.
} 
leads to morning and evening traffic jams and noise from cars; office areas become more dangerous at night, etc. To account for both the positive and the negative externalities, $\mathrm{Li}$ and Brown (1980) suggest to use a logarithmic distance function to represent the positive accessibility effect and a negative exponential function for the negative externality effect, thus defining the net effect of proximity on house $i$ as:

$$
\operatorname{prox}\left(D_{i}\right)=\gamma \ln \left(D_{i}+e\right)+\phi\left(-\exp \frac{-D_{i}}{\lambda}\right)
$$

where $D_{i}$ is the distance from the house to the EC headquarters; e is the contant $2.718, \gamma, \phi$ and $\lambda$ are parameter. This form is used in the equation which is estimated by nonlinear least-squares. For negative $\gamma$, the first term is decreasing with distance; for positive $\phi$ (and $\lambda$ ), the second term is increasing with distance. The advantage of such a specification is that $\operatorname{prox}\left(\mathrm{D}_{\mathrm{i}}\right)$ is not necessarily a monotonic function.

Impact of "Edinburgh decisions" and the 1992 Single Market 9

Land rents may have increased in anticipation of the decision of the Commission to remain in Brussels and of the Parliament to move to Brussels, compounded by the move to the "Single Market" in 1992.

To test for this effect, we checked whether the coefficients of the hedonic price equation changed between the periods 1980-1987 and 1988-1992. If so, the resulting land rent appreciations can be obtained from a comparison of the coefficients associated to the variables which measure the distance to EC headquarters. This procedure will be carried out using both specifications (2.4) and (2.5).

\section{Data and results}

Our database consists of 2,095 single-family houses sold in Brussels between 1980 and 1992. The characteristics that we use are often those encountered in hedonic price equations for housing. They can be classified into three groups: (1) those that are fully exogenous to the property: year of sale 10 and type of sale (auction or private); (2) those describing the estate itself (year of construction, type of house, lot size, number of

\footnotetext{
${ }^{9}$ For ease of exposition, we call "Edinburgh decision," the expected decision to leave the headquarters in Brussels, though the decision was only made in December 1992.

${ }^{10}$ Here we assume, as is often done, that the prices of characteristics remain constant over the years during which sales are observed.
} 
floors, other structure and site attributes like bathroom, garden, garage, etc.), evaluation by an expert of the structure and maintenance qualities; (3) variables measuring neighbourhood attributes, including accessibility to the closest public parc, to a subway sation as well as chemical pollution and location qualities evaluated by an expert. ${ }^{11}$ Finally, the characteristic we are most interested in is the distance to EC headquarters.

Note that our database consists of houses and neither flats nor office space, though the number of housing possibilities in the direct neighbourhood of the EC is rather limited. The main reason is that data on house transactions are more easily available and more numerous than those on offices. In any case, even if the values of houses and office space differ, there are good reasons to think that price movements are similar since, especially in the EC neighborhood, many houses have been either turned into offices or knocked down to build offices.

The results were estimated by ordinary least squares, using specification (2.4) for distance with respect to the EC and by nonlinear least squares, ${ }^{12}$ using specification (2.5). We do not give the results obtained by OLS (except for the distance to EC variables, which will be discussed later), since they are very close to those obtained by nonlinear least squares, which are reproduced in Appendix 2. Before turning to the influence due to the EC, we briefly discuss the effects of purely exogenous factors as well as those of the qualities of the houses and their neighborhood attributes.

\section{Purely exogenous factors}

The exogenous time trend for prices is constructed on the basis of the coefficients picked by the annual dummies and is shown in Figure $1 .{ }^{13}$ It should be noted that prices have started to increase in 1987, but this was the case in most European cities around 1987, so that the mere increase can hardly be attributed to the anticipated establishment of the European Parliament in Brussels. To remain on firm ground and provide a (lower) bound to the effect of the EC, we shall assume that this increase is due to factors that are not linked to the EC.

\footnotetext{
11 See Appendix 1 for more details.

12 The nonlinear equation was first estimated using ordinary least squares and a starting value of 500 for $\lambda$; the estimated coefficients were then used as starting values for the nonlinear routine.

13 To compute the time trend over the whole period 1980-1992, we run two regressions: one from 1980 to 1987 and the second one from 1987 to 1992 . The year 1987 is common to both regressions in order to patch the coefficients.
} 
Figure 1

Price index $(1980=100)$

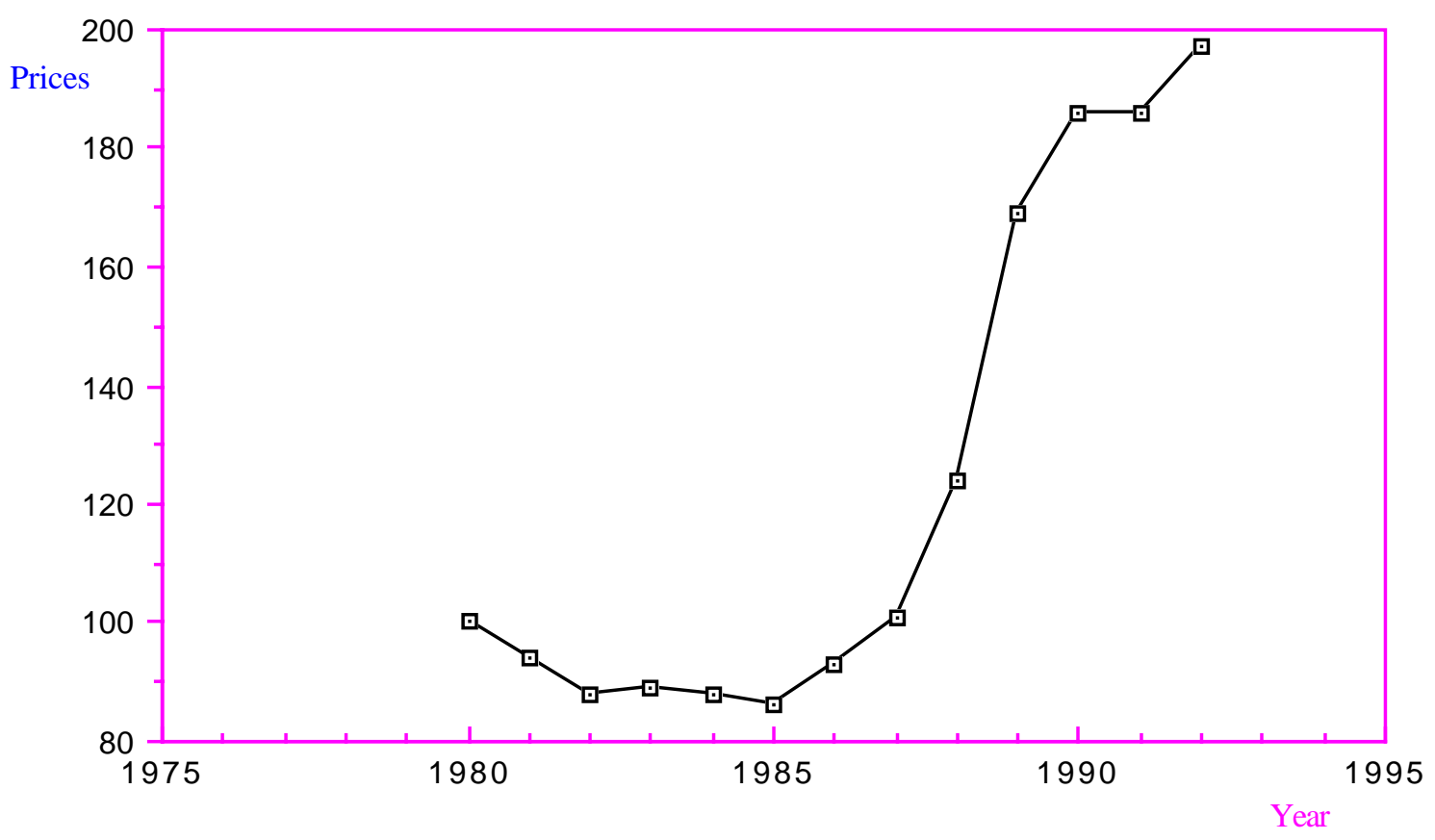

Qualities of the properties and neighborhood attributes

Most of the parameters have the expected sign and add significantly to the explanation of prices. "House types" are an interesting exception to this rule: the distinction among the four varieties considered is hardly significant; the reason is probably that the typology is superfluous given all the other characteristics. It is also worth noting that the relative importance between lot size and construction size matters greatly: houses cannot become too large with respect to the size of the lot (viz. the negative sign of the coefficient "constructed area, in \% of lot area").

Rents due to the EC headquarters

Results based on relation (2.4) that are displayed in Table 1 show that during the period 1980-1987, the EC has generated positive rents on nearby houses, but these rents decrease very quickly and are not significantly different from zero after $3,000 \mathrm{~m}$. The increase in prices is however approximately equal to $17 \%$ in the close neighborhood (radius of $1,000 \mathrm{~m}$ ), drops to some $11 \%$ between 1,000 and $2,000 \mathrm{~m}$. The increase between 2,000 and 3,000 meters is probably due to a better environment, not captured fully by the neighborhood variables that we use. This suggests that the two effects (positive as well as 
negative externalities) described by equation (2.5) are present; the estimation results of Appendix 2, lead to the index presented in the lower part of Table $1 .{ }^{14}$ The two indices give roughly the same orders of magnitude for the first subperiod (1980-1987).

Table 1

Rent appreciations

\begin{tabular}{|c|c|c|c|c|c|c|c|}
\hline & & \multicolumn{3}{|c|}{$1980-1987$} & \multicolumn{3}{|c|}{ 1988-1992 } \\
\hline & & Coeff. & St. dev. & Index & Coeff. & St. dev. & Index ${ }^{*}$ \\
\hline \multicolumn{8}{|c|}{ Ordinary least squares - relation (2.4) } \\
\hline 0-1000m & & 0.157 & 0.071 & 117 & 0.710 & 0.109 & 203 \\
\hline $1000-2000 \mathrm{~m}$ & & 0.110 & 0.056 & 111 & 0.399 & 0.085 & 149 \\
\hline $2000-3000 \mathrm{~m}$ & & 0.187 & 0.054 & 120 & 0.329 & 0.082 & 139 \\
\hline $3000-4000 \mathrm{~m}$ & & 0.047 & 0.050 & 105 & 0.273 & 0.079 & 131 \\
\hline $4000-5000 \mathrm{~m}$ & & 0.059 & 0.050 & 106 & 0.174 & 0.078 & 119 \\
\hline $5000-6000 \mathrm{~m}$ & & 0.079 & 0.048 & 108 & 0.150 & 0.074 & 116 \\
\hline $6000-7000 \mathrm{~m}$ & & 0.020 & 0.050 & 102 & 0.034 & 0.076 & 103 \\
\hline More than $7000 \mathrm{~m}$ & & 0.000 & - & 100 & 0.000 & - & 100 \\
\hline \multicolumn{8}{|c|}{ Nonlinear least squares - relation $(2.5)$} \\
\hline $500 \mathrm{~m}$ & & & & 110 & & & 218 \\
\hline $1500 \mathrm{~m}$ & & & & 114 & & & 159 \\
\hline $2500 \mathrm{~m}$ & & & & 113 & & & 145 \\
\hline $3500 \mathrm{~m}$ & & & & 109 & & & 135 \\
\hline $4500 \mathrm{~m}$ & & & & 106 & & & 125 \\
\hline $5500 \mathrm{~m}$ & & & & 104 & & & 116 \\
\hline $6500 \mathrm{~m}$ & & & & 102 & & & 107 \\
\hline $7500 \mathrm{~m}$ & & & & 100 & & & 100 \\
\hline
\end{tabular}

These rents are much larger during the period 1988-1992 (over 100\% in the close neighborhood of the EC, and still some $50 \%$ at a radial distance of $1,500 \mathrm{~m}$ ); moreover, positive externalities due to the EC seem to dominate, since the gradient of prices decreases monotonically with distance to the center. Again, estimates obtained by OLS and nonlinear least squares are of the same order of magnitude.

Rent appreciations 14 These calculations assume that the effect is zero at a distance of $7,500 \mathrm{~m}$ (i.e. the result obtained by
OLS estimation). 
We now turn to the "Edinburgh" and the "1992" impacts, which we measure by the differential in rents between 1980-1987 and 1988-1992. We first have to test whether the coefficients are significantly different across the two periods, i.e. whether a structural change really took place. ${ }^{15}$ The various results of the tests are reproduced in Table 2.

Table 2

Hypothesis testing

\begin{tabular}{|c|c|c|c|c|c|}
\hline Hypothesis tested & $\begin{array}{c}\text { Residual sum } \\
\text { of squares } \\
\text { Log lokelihood** }\end{array}$ & $\begin{array}{l}\text { Variables in } \\
\text { the model }\end{array}$ & $\begin{array}{l}\text { Degrees of } \\
\text { freedom }\end{array}$ & $\begin{array}{c}\text { F-test }^{*} \\
\text { Log likelihood } \\
\text { ratio-test }\end{array}$ & $\begin{array}{c}\text { Tabulated } \\
\text { value } \\
(1 \%)\end{array}$ \\
\hline
\end{tabular}

Model estimated by OLS (specification (2.4))

All coefficient different $\quad 192.45 \quad 101$

All coefficients different

except distance

196.26

94

7 and 1994

5.62

2.65

Only distance coefficients

are different

203.96

63

38 and 1994

3.13

1.20

All coefficients equal

216.19

56

45 and 1994

5.46

1.00

\section{Model estimated by nonlinear LS (specification (2.5))}

All coefficients different

$-498.28$

97

All coefficients different except distance

$-480.10$

94

$3 \quad 36.36$

11.34

\footnotetext{
* For the model estimated by OLS.

** For the model estimated by nonlinear least squares.
}

The basic model against which alternative hypotheses are tested is a model in which all coefficients are allowed to be different across the two subperiods (except of course the annual dummies). The model estimated by OLS includes 101 variables. ${ }^{16}$ Three types of restrictions are imposed: (i) the "distance to CE" coefficients are the only ones to be equal over the two subperiods; (ii) all coefficients are equal, except the "distance to CE" coefficients which are allowed to vary across periods; (iii) all coefficients are equal. The three restrictions are strongly rejected, but the important point here is that the equality for the "distance to $\mathrm{CE}$ " coefficients is strongly rejected. The same conclusion holds for the nonlinear model (viz. the likelihood ratio test in Table 2).

\footnotetext{
15 Note that this structural change may have happened in a smoother way than under the form of a break at a certain moment; the importance here is that a change took place between the two subperiods.

1611 annual dummies, 14 distance to CE dummies (i.e. 7 variables for each subperiod), 76 other characteristics (i.e. 38 variables for each subperiod).
} 
The tests show that, even if we let the coefficients for characteristics vary between the two subperiods, the distance to EC coefficients are strongly different: distance plays a much larger role in recent (i.e. post-1987) than in earlier years. Rents that result from the EC headquarters have increased dramatically: while the price of a house in a $1,000 \mathrm{~m}$ radius of the EC was some $17 \%$ higher than the same house at a distance of $7,500 \mathrm{~m}$ in the mid-eighties, the difference reaches over $100 \%$ in the early nineties. This change is illustrated in Figure 2 (using the coefficients of the nonlinear model). It should be clear that these differences do not include the general price increase of Figure 1, which is accounted for by the yearly dummy variables.

Figure 2

Impact of the EC

Rent Index $(7,500 \mathrm{~m}=100)$

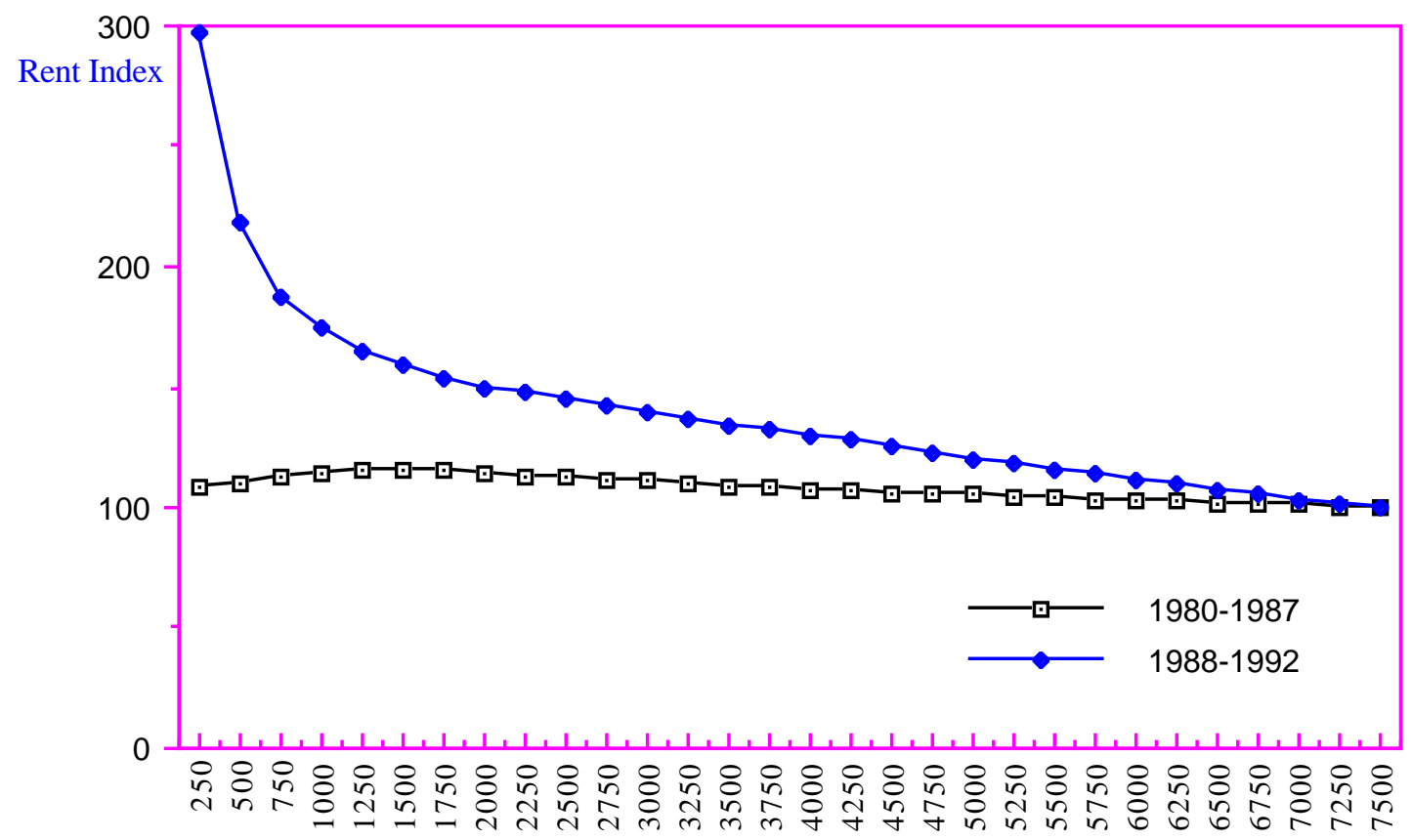




\section{Conclusion}

The main purpose of the paper was to estimate the rents accruing to property values, generated by the "old" (i.e. pre-1988) EC headquarters, and those which result from the decision (made in Edinburgh in 1992 but already anticipated in 1987) to leave the headquarters in Brussels and to hold there the additional sessions (and probably others also) of the European Parliament.

In order to separate the pure EC effect from other effects, we use a hedonic regression framework, including as many characteristics as possible of houses sold in Brussels between 1980 and 1992. The hedonic approach is meant to homogenize prices of properties of different qualities.

The empirical results show that the impact of the EC is very large in a close neighborhood of the EC headquarters, but that the influence is still meaningful (in the order of $25 \%$ ) at a distance of $3,500 \mathrm{~m}$.

It is useful to point out that the rents considered here are proportional to the value of the property, including the building. This is the basis of our data, since the number of transactions on land would obviously be much too small to derive any statistically convincing conclusion. This implies that the resulting capital gains on land itself are much higher. There is little doubt that the property tax structure in Brussels should take this into account, and tax away at least part of these windfall profits (preferably by following a nonlinear schedule similar to the one represented in Figure 2) to finance public infrastructure. ${ }^{17}$

\section{References}

Bailey, M., R. Muth and H. Nourse (1963), A regression method for real estate price index construction, Journal of the American Statistical Association 58, 933-942.

Bartik, T. (1987), The estimation of demand parameters in hedonic price models, Journal of Political Economy 95, 81-88.

Brown, J. and H. Rosen (1982), On the estimation of structural hedonic price models, Econometrica 50, 765-768.

Case, B. and J. Quigley (1991), The dynamics of real estate prices, Review of Economics and Statistics 73, 50-58.

17 See the paper by Drèze (1992), building on ideas introduced by Vickrey (1977) and Kanemoto (1980, chap. 2). The results should however be extended to deal with uncertainty. 
Chanel, O., L.-A. Gérad-Varet and V. Ginsburgh (1992), The relevance of hedonic price indices: the case of paintings, manuscript.

Drèze, J. (1995), La ville, le marché et les pouvoirs publics, in J. Drèze (1995), Pour l'Emploi, la Croissance et l'Europe, Bruxelles: De Boeck-Wesmael.

Epple, D. (1987), Hedonic prices and implicit markets: estimating demand and supply functions for differentiated products, Journal of Political Economy 95, 59-80.

Grether, D.M. and P. Mieszkowski (1974), Determinants of real estate values, Journal of Urban Economics 1, 127-146.

Griliches, Z., ed. (1971), Price Indices and Quality Change, Cambridge: Harvard University Press.

Halvorsen, R. and H.O. Pollakowski (1981), Choice of functional forms for hedonic price equations, Journal of Urban Economics 10, 37-49.

Kanemoto, Y. (1980), Theories of Urban Externalities, Amsterdam: North-Holland

Li, M.M. and H.J. Brown (1980), Micro-neighborhood externalities and hedonic housing price, Land Economics 56, 125-141.

Linneman, P. (1980), Some empirical results on the nature of the hedonic price function for the urban housing market, Journal of Urban Economics 8, 47-68.

Nelson, J.P. (1978), Residential choice, hedonic prices and the demand for urban air quality, Journal of Urban Economics 5, 357-369.

Palmquist, R. (1980), Alternative techniques for developing real estate price indexes, Review of Economics and Statistics 62, 442-448.

Palmquist, R. (1982), Measuring environmental effects on property values without hedonic regressions, Journal of Urban Economics 11, 333-347.

Palmquist, R. (1984), Estimating demand for the characteristics of housing, Review of Economics and Statistics 66, 394-404.

Rosen, S. (1974), Hedonic prices and implicit markets: product differentiation in pure competition, Journal of Political Economy 82, 34-55.

Shiller, R. (1991), Arithmetic repeat sales estimators, Journal of Housing Economics 1, $110-126$.

Vickrey, W. (1977), The city as a firm, in The Economics of Public Services, London: MacMillan.

Witte, A., H. Sumka and H. Erekson (1979), An estimate of a structural hedonic price model of the housing market: an application of Rosen's theory of implicit markets, Econometrica 47, 1151-1173. 


\section{Appendix 1. Characteristics used in regressions}

\section{(1) Exogenous factors}

Year of sale (dummy variables; 13 years - 1980 to 1992).

Type of sale (dummy variables; auction or private).

\section{(2) Attributes of the properties}

Year of construction (dummy variables; 10 classes - before 1900; 1900-09; 1910-19; 1920-29; 193039; 1940-49; 1950-59; 1960-69; 1970-79; later than 1980).

Experts' evaluation of the structure (dummy variables; 3 classes - good, average, bad).

Experts' evaluation of maintenance (dummy variables; 3 classes - good, average, bad).

Number of floors (dummy variables; 3 classes - two; three; more than three).

Type of house (dummy variables; 5 classes - Villa: house surrounded by a garden; Maison de Maître: bourgeois house, usually built between 1900 and 1920; Maison de rapport: house subdivided into flats and rented to several families; Bel étage: three-façade house; Other: any other single family house).

\section{Other structure and site attributes}

Construction area (sq.meters).

Unconstructed area (sq. meters).

Construction area (in \% of lot size).

Width of façade (meters).

Bathroom (dummy variable; means at least one bathroom).

Central heating (dummy variable).

Equipped kitchen (dummy variable).

Garden (dummy variable).

Garage (dummy variable; means at least one garage).

Basement (dummy variable; means a basement which can be used as living area).

\section{(3) Neighborhood attributes}

Pollution (in $\mu$ /cub.meter)

$\mathrm{NO}_{2}$ (2 classes - less than $40 \mu$; more than $40 \mu$ at percentile 50 ).

$\mathrm{SO}_{2}$ (2 classes - less than $40 \mu$; more than $40 \mu$ all at percentile 98).

Particles in suspension ( 2 classes - less than $10 \mu$; more than $20 \mu$ all at percentile 98).

Experts' evaluation of location (dummy variables; 3 classes - good, average, bad).

\section{Other}

Distance to closest park $(\mathrm{Km})$.

Distance to closest subway $(\mathrm{Km})$.

(4) Distance to EC (dummy variables; 8 classes of distances in meters - 0 to 999; 1000 to $1999 ; 200$ to 2999 ; 3000 to 3999 ; 4000 to 4999 ; 5000 to 5999 ; 6000 to 6999 ; more than 7000 ). 


\section{Appendix 2 \\ Regression results}

$1980-1987$

1988-1992

Coeff. St. dev. Index ${ }^{*}$ Coeff. St. dev. Index*

\section{(1) Exogenous factors}

Year of sale

\begin{tabular}{|c|c|c|c|c|c|}
\hline 1980 & 0.000 & - & 100 & & \\
\hline 1981 & -0.067 & 0.037 & 93 & & \\
\hline 1982 & -0.126 & 0.037 & 88 & & \\
\hline 1983 & -0.113 & 0.037 & 89 & & \\
\hline 1984 & -0.125 & 0.036 & 88 & & \\
\hline 1985 & -0.154 & 0.035 & 86 & & \\
\hline 1986 & -0.076 & 0.034 & 93 & & \\
\hline 1987 & 0.003 & 0.034 & 100 & & \\
\hline 1988 & & & 0.000 & 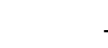 & 100 \\
\hline 1989 & & & 0.309 & 0.035 & 136 \\
\hline 1990 & & & 0.415 & 0.037 & 151 \\
\hline 1991 & & & 0.403 & 0.041 & 150 \\
\hline 1992 & & & 0.458 & 0.049 & 158 \\
\hline
\end{tabular}

Type of sale

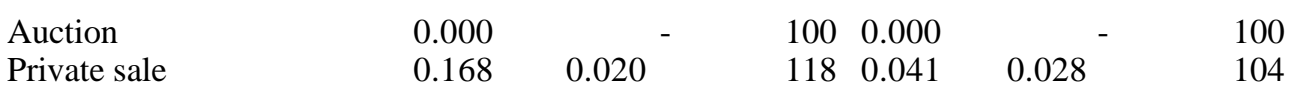

(2) Attributes of the properties

Year of construction

$\begin{array}{lrlrrrr}\text { Before 1900 } & -0.108 & 0.058 & 90 & -0.028 & 0.076 & 97 \\ 1900-1909 & 0.000 & & 100 & 0.000 & & 100 \\ 1910-1919 & 0.023 & 0.033 & 102 & 0.084 & 0.044 & 108 \\ 1920-1929 & 0.152 & 0.036 & 116 & 0.191 & 0.046 & 121 \\ 1930-1939 & 0.253 & 0.037 & 129 & 0.274 & 0.049 & 132 \\ 1940-1949 & 0.339 & 0.070 & 140 & 0.193 & 0.091 & 121 \\ 1950-1959 & 0.305 & 0.043 & 136 & 0.267 & 0.060 & 130 \\ 1960-1969 & 0.327 & 0.051 & 139 & 0.220 & 0.074 & 125 \\ 1970-1979 & 0.396 & 0.090 & 149 & 0.167 & 0.122 & 121 \\ \text { After } 1980 & 0.498 & 0.136 & 165 & 0.106 & 0.114 & 111\end{array}$

Experts' evaluation of the structure

\begin{tabular}{|c|c|c|c|c|}
\hline Good & 0.060 & 0.043 & $106 \quad 0.079$ & 0.052 \\
\hline Average & 0.000 & - & $100 \quad 0.000$ & \\
\hline $\mathrm{Bad}$ & -0.043 & 0.022 & $96-0.085$ & 0.036 \\
\hline
\end{tabular}

Experts' evaluation of the maintenance

\begin{tabular}{|c|c|c|c|c|c|}
\hline Good & 0.019 & 0.031 & $102 \quad 0.070$ & 0.039 & 107 \\
\hline Average & 0.000 & - & $100 \quad 0.000$ & & 100 \\
\hline $\mathrm{Bad}$ & -0.120 & 0.020 & $89-0.102$ & 0.031 & 90 \\
\hline
\end{tabular}

\footnotetext{
* The index is computed as $\exp (\beta)$, where $\beta$ is the regression coefficient.
} 


\section{Appendix 2 (cont.) \\ Regression results}

1980-1987

1988-1992

Coeff. St. dev. Index ${ }^{*}$ Coeff. St. dev. Index*

Number of floors

Two

$-0.033$

Three

0.000

$97-0.087$

0.028

92

More than three

$0.145 \quad 0.042$

$115 \quad 0.111$

0.071

100

111

Type of house

Villa

$\begin{array}{rrrrr}0.024 & 0.047 & 102 & 0.079 \\ 0.050 & 0.077 & & 105 & 0.198 \\ -0.151 & 0.143 & 85 & 0.009 \\ 0.204 & 0.157 & & 123 & -0.137 \\ 0.000 & & - & 100 & 0.000\end{array}$

0.080

109

Maison de maître

$123-0.137$

0.140

122

Bel étage

0.000

0.080

101

0.170

100

Other structure and site attributes

Constructed area (100 sq. m) 0.562

Unconstructed area (100 sq. m) 0.014

Constructed area (\% lot size)-0.577

Width of facade (in $\mathrm{m}$ )

0.005

Bathroom(s)

0.172

Central heating

Equipped kitchen

0.240

0.160

0.126

arden

0.083

Garage

Basement
0.047

0.005

0.071

0.002

0.021

0.023

0.026

0.027

0.023

0.065

$\begin{array}{rrrr} & 0.993 & 0.087 & \\ & 0.012 & 0.009 & \\ -0.646 & 0.112 & \\ & 0.003 & 0.004 & \\ 119 & 0.146 & 0.032 & 116 \\ 127 & 0.139 & 0.034 & 115 \\ 117 & 0.098 & 0.034 & 110 \\ 113 & 0.081 & 0.043 & 108 \\ 108 & 0.098 & 0.034 & 110 \\ 104 & 0.151 & 0.072 & 116\end{array}$

\section{(3) Neighborhood attributes}

\section{Pollution}

NO2 (below 40u)

NO2 (above 40u)

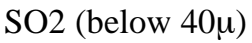

SO2 (above 40u)

Dust (below 40u)

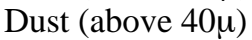

$\begin{array}{rrrrrr}0.000 & & 100 & 0.000 & & - \\ -0.016 & 0.038 & 98 & -0.128 & 0.059 & 100 \\ & & & & & 88 \\ 0.000 & - & 100 & 0.000 & - & 100 \\ -0.076 & 0.032 & 93 & -0.101 & 0.044 & 90 \\ & & & & & - \\ 0.000 & & 100 & 0.000 & & -100 \\ -0.128 & 0.028 & 88 & -0.138 & 0.041 & 87\end{array}$

Expert's evaluation of the location

\begin{tabular}{|c|c|c|c|c|}
\hline Good & 0.095 & 0.032 & $110 \quad 0.132$ & 0.035 \\
\hline Average & 0.000 & - & 1000.0000 & 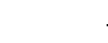 \\
\hline $\mathrm{Bad}$ & -0.182 & 0.022 & $83-0.186$ & 0.040 \\
\hline
\end{tabular}

Other attributes

$\begin{array}{lllrr}\text { Distance to parc }(\mathrm{Km}) & -0.587 & 0.250 & -0.244 & 0.353 \\ \text { Distance to subway }(\mathrm{Km}) & -0.203 & 0.102 & 0.003 & 0.155\end{array}$

\footnotetext{
* The index is computed as $\exp (\beta)$, where $\beta$ is the regression coefficient.
} 


\section{Appendix 2 (cont.)}

Regression results

\begin{tabular}{|c|c|c|c|c|c|}
\hline & \multicolumn{2}{|c|}{$1980-1987$} & \multicolumn{3}{|c|}{$1988-1992$} \\
\hline & Coe & St. dev. & Index $^{*}$ & f. St. dev. & Index $^{*}$ \\
\hline \multicolumn{6}{|l|}{ (4) Distance to EC } \\
\hline $\begin{array}{l}\gamma \\
\phi \\
\lambda\end{array}$ & $\begin{array}{c}-0.118 \\
0.468 \\
669.19\end{array}$ & $\begin{array}{l}0.052 \\
0.232 \\
432.29\end{array}$ & $\begin{array}{l}-0.640 \\
-1.258 \\
2017.88\end{array}$ & $\begin{array}{l}0.262 \\
0.806 \\
458.39\end{array}$ & \\
\hline Intercept & 14.917 & 0.446 & 19.700 & \multicolumn{2}{|l|}{2.340} \\
\hline \multicolumn{2}{|c|}{ Quality of adjustm. ( $\left.\mathbf{R}^{2}\right)$} & & \multicolumn{2}{|c|}{0.807} & \\
\hline \multicolumn{2}{|l|}{$\mathrm{Nb}$ of observations } & 1386 & \multicolumn{3}{|c|}{709} \\
\hline
\end{tabular}

\footnotetext{
${ }^{*}$ The index is computed as $\exp (\beta)$, where $\beta$ is the regression coefficient.
} 